\title{
Formation of ecological culture of the person in agriculture
}

\author{
Denis Nedbaev ${ }^{l}$, Svetlana Nedbaeva ${ }^{l *}$, Oksana Goncharova ${ }^{l}$, Julia Kochurina $^{1}$, and \\ Varvara Tkachenko ${ }^{1}$ \\ ${ }^{1}$ Armavir Social-Psychological Institute, Private Educational Institution of Higher Education, \\ Komsomolskaya St., 127, Armavir, Krasnodar region, 352900, Russia
}

\begin{abstract}
The article discusses the formation of an "Ecological man" by means of psychological practices in the realities of the agricultural sector of the Krasnodar Region. The authors revealed the nature, content and characteristics of the impact of environmental anthropogenic factors on the "environmental man"; determined the criteria and conditions for the formation his ecological culture at the present stage in the realities of modern agribusiness; investigated the state of greening of rural areas of the Krasnodar Region; considered psychological practices as an effective technology for adaptation and life of the "environmental man" in the realities of the agricultural sector. The study allowed: to justify the need for the formation of an "Ecological man" and to propose a system of environmentally-oriented psychological practices for its formation and development, while simultaneously contributing to an increase in the efficiency of the agricultural sector; propose supplementing the monitoring of the ecology system of the Krasnodar Region with psychoecological and mediaecological components; to identify the possibility of highlighting the content of environmental values that determine self-development of a person and a change in attitude to the world. The agro-industrial complex must take on the strategy of creating and managing an informational ecological environment.
\end{abstract}

\section{Introduction}

Significant events that can be classified as psychotraumatic are increasingly happened with modern man. These events give numerous examples of the negative impact of external conditions on human development. They have a different origin, heterogeneous nature. Civilization processes have the greatest impact on a person through the information component, which transforms him into an information subject. At the same time, information can make a significant contribution to the formation of a new, ecological ideology, where the primary role will be given to the spiritual sphere, traditional human values, and new technologies will become a means to establish harmony of man, wildlife and technological innovations, without which the modern world is unthinkable. And here a key role can and should be played by a person of high ecological culture, educated, creative

\footnotetext{
* Corresponding author: sv11411@mail.ru
} 
and moral, capable of objectively assessing the situation and defending his ideas «Ecological man». [1, 2, 3] In the scientific world, questions about the role of information in the field of politics and economics in the face of accelerated technological progress are being actively developed, and interest in studying the ecological and psychological environment has intensified. The emphasis is on the existence of an inextricable link between a person and the conditions in which he lives and works. [4, 5, 6] However, to date, very little attention has been paid to the influence of information flows on such an important area as ecology; man's ideas about the role of semantic information factors in the life process have not been studied much. It becomes obvious that a person, being in the rapidly changing conditions of his existence, needs psychological support. Such support may have a personal orientation, and may relate to the conditions in which the activity is carried out. Strengthening psychoecological resources and determining psychological inclusions, in this case, are no less important than economic and social components. [7, 8]

Purpose: the formation of the "environmental man" by means of psychological practices in the realities of the agricultural sector of the Krasnodar Region, the identification of conditions that ensure its effectiveness.

Project Tasks: 1) to analyze the environmental anthropogenic factors in the agricultural sector of the Krasnodar Region; 2) to identify the nature, content and characteristics of the impact of environmental anthropogenic factors on the "environmental man" in the realities of the agricultural sector; 3 ) to determine the criteria and conditions for the formation of the "environmental man", his ecological culture at the present stage in the realities of modern agribusiness; 4) to study the state of greening of rural areas of the Krasnodar Region based on data from social networks on the Internet; 5) to consider psychological practices as an effective technology for adaptation and life of the "environmental man" in the realities of the agricultural sector.

Hypothesis: The ecological culture of the personality acts as a process of the subject's internal activity, based on personal and social experience, under the influence of objective factors of the social, informational and natural environment, as well as the conditions of education, eco-education and self-education of himself as a subject of life and a subject of nature.

The Russian economy is based on natural resource, demographic, industrial, technological and infrastructural development factors. One of the main areas of economic activity in the Krasnodar Region is agriculture. Technogenic pressure poses threats to the economic activity of the agro-industrial complex and negatively affects the health of the population of the Kuban. Lack of interest, inertness of economic entities in environmental modernization of production limits development and reduces the advantages of the Russian economy, leading the country to a number of serious socio-cultural, economic and environmental challenges. Constraining factors for the implementation of environmental policy strategies are non-compliance with the principles of sustainable development, which provides for equal attention to its economic, social and environmental components; the dominance of economic efficiency, including at the cost of violating environmental norms and standards; low level of ecological culture of the population, lack of environmental education system, market of environmental services, accessible environmental technologies, irresponsibility for the use of natural resources, ambiguous impact of information flows on ecology and psychoecology, etc. [3, 9, 10] Today, a fairly high pace of transformation in the field of state economic policy has already been set. The Russian Federation joined the WTO, which implies the fulfillment of a number of requirements, including international environmental obligations. The National Ecology Doctrine, the new Food Security Doctrine, and the Declaration on the Implementation of the Green Economy Principles in the Russian Federation were adopted. The "green" economy is aimed at improving the ecological construct of the modern person - the "Ecological Man", ensuring 
a high level of quality of life for the population based on economic prosperity, including the agro-industrial complex, as well as creating a safe environment for health; careful and rational use of natural resources in the interests of future generations. [11]

\section{Materials and Methods}

Place of research: Krasnodar Region.

Keywords: "Ecological man", psychological practices, agro-industrial complex, Krasnodar Region, technologies, ecological Internet environment, environmental psychology, "green economy", information ecology, environmental policy, ecology of media space, psychological security.

Assumptions made and their rationale: intervals of discrete quantities.

Methods: survey (questioning, interviewing, conversation); projective techniques (unfinished proposal, ranking); methods of mathematical-statistical and graphic processing; monitoring of social networks on the Internet, agroecological analysis, study-analysis of the products of activity, content analysis of electronic media and others.

\section{Results}

According to state reports on the state of nature management and environmental protection in the Krasnodar Region over the past 10 years, the territory of the Krasnodar Region has found itself in an ecological state of concern (fig. 1).

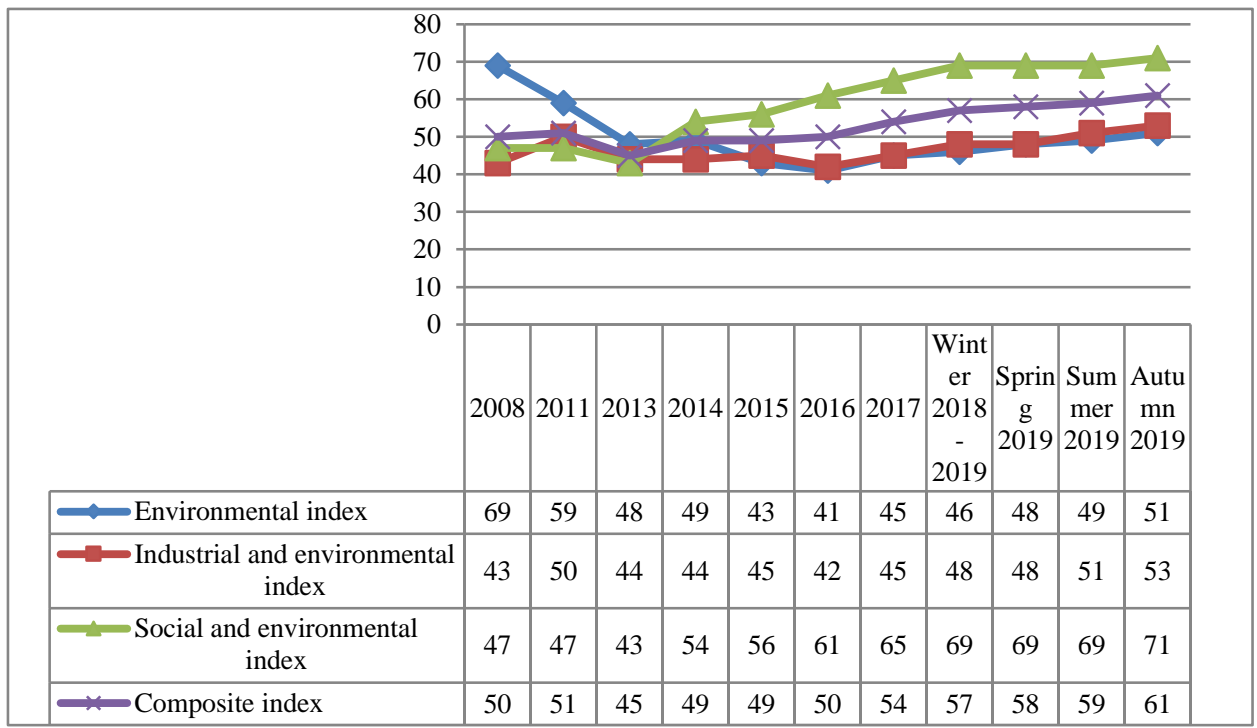

Fig. 1. National environmental rating of Krasnodar Region (2008-2019).

According to the National Ecological Rating of the Subjects of the Russian Federation since 2008, the most critical index has been the environmental index. If since 2008 the index was 69, then by 2013 it fell by 21 points, the decline continued until 2016, and gradual growth was indicated in 2017, however, the indicators for the fall of 2019 have not yet reached the initial values $(-18)$.

Despite the current situation in most agro-industrial complex, a thorough environmental assessment is not carried out at present, sources of pollution of soils, ground and surface 
waters, agricultural products, etc. are not inventoried. Agrarian and industrial complex in modern conditions continues to be the main polluter of the earth and the whole environment in rural areas (Fig. 2). A number of environmental problems of agricultural production primarily related to environmental pollution.

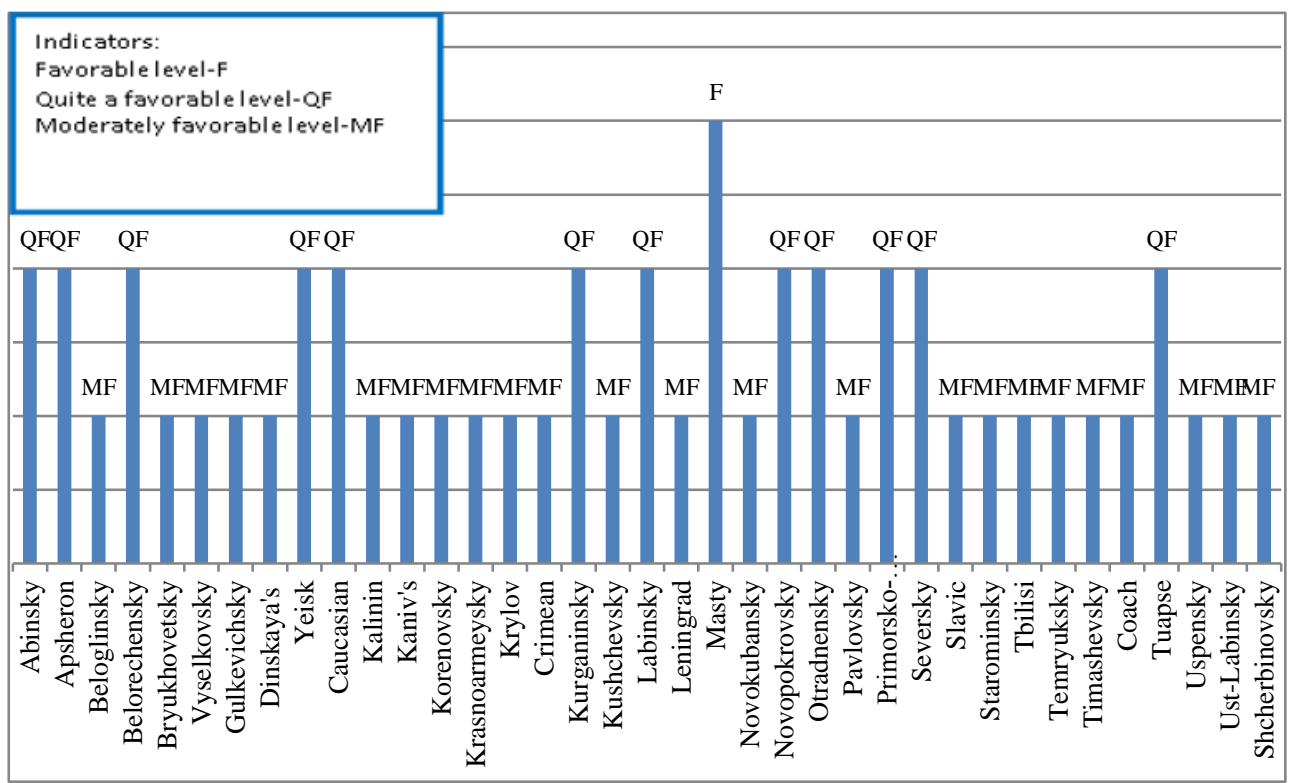

Fig. 2. The average level of atmospheric pollution (2012-2018).

The conducted content analysis of electronic media (25 sites) of the Krasnodar Region made it possible to determine the statistical mode of the components of ecology. The results are shown in Figure 3.

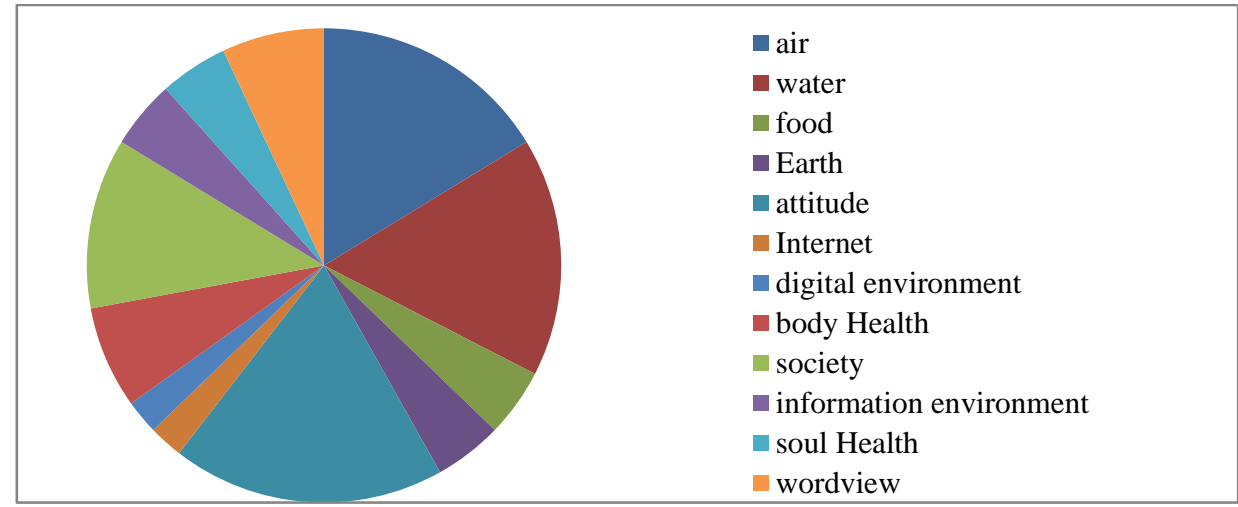

Fig. 3. Social Network Research.

Conducted researches have confirmed the criticality of the environmental index.

Future farmers were asked to rank 12 statements related to the environmental components studied in social networks. Data of respondents are shown in graphs (Fig. 4). 


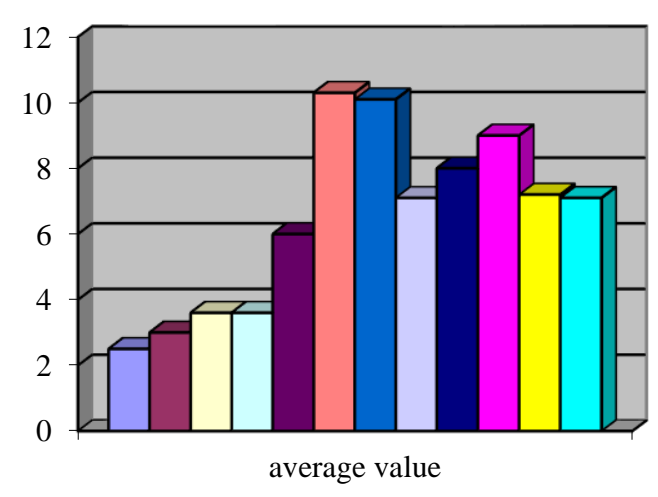

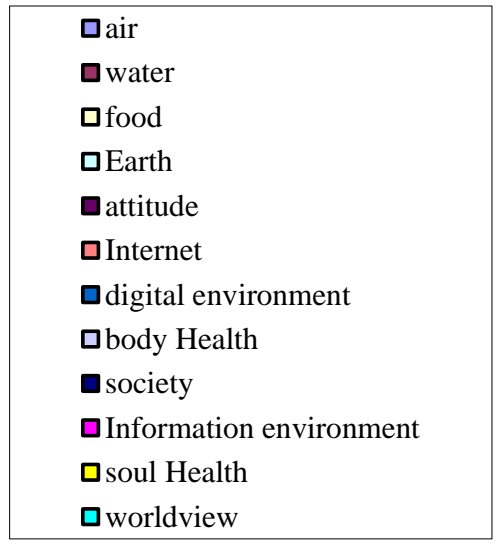

Fig. 4. The research of environmental components by respondents.

Thus, we can conclude that measures taken by people themselves, municipal, regional and federal authorities, public organizations, show their lack of effectiveness. In today's changing world, environmental dangers are mounting. In order to prevent an environmental catastrophe, great efforts are needed both from state institutions and civil society institutions, as well as understanding the processes taking place in the field of information and communication, their impact on the economic, environmental and educational components [12], the flexible development of the "digital agroecosystem" [3, 5, 10, 13], the search for ways to transition agriculture to digital technology. In the conditions of the Krasnodar Region there is a gap, inequality between the "city" (people not employed in the field of rural labor) and the "village" (people employed in the field of agriculture).

Internet coverage areas 3G/4G (Tele2, MTS, Megafon, Beeline, Yota) of Krasnodar Region are completed each other. However, in mountainous and foothill areas, the Internet is low or absent. In rural areas, the Internet is also developed close to highways. However, the development trend of Internet coverage is improving every year. The Internet in the Krasnodar Region is best developed in the large cities (Krasnodar, Armavir, Novorossiysk, Sochi). There is a bigger coverage of $4 \mathrm{G}$ in cities than in countryside. A powerful tool for influencing the formation of an "environmental man" is the information environment and the possibilities of environmentally oriented psychological practices.

\section{Discussion}

"Virtual psychological practice (aretea) is distinguished by the type of organization of influence and interaction in the system "Man - virtual reality", "Man - nature" and others $[14,15,16]$.

According to the theory of human-technical systems, their leading factor is the joint activity of man, in which the technical component (electronic information carrier) acts only as a means of its effective self-realization. This means how the components (information and telecommunication) of the Internet environment fit into the structure of human activity, its needs, motives, goals and actions. Using the virtual environment is not only technically feasible, cost-effective, but also the social demand for the provision of psychological services. In this regard, there is a need to develop an eco-ecological policy, create new social movements with the aim of promoting environmental ideas in the Internet environment [17], develop educational programs for the formation of environmental consciousness (including info-ecological and psycho-ecological), operationalize 
psychological practices in information and communication space in the realities of the agroindustrial complex.

Thus, the studies were performed in the planned volume, the hypothesis was confirmed.

\section{Conclusions}

The research allowed: 1) to substantiate the need for the formation of an "Ecological Man" and to propose a system of environmentally oriented psycho-practitioners for its formation and development, while improving the economic activity in the development of the agroindustrial complex; 2) to propose supplementing the monitoring of the ecology system of the Krasnodar Region with psychoecological and mediaecological components; 3) to identify the possibility of highlighting the content of environmental values that determine self-development of a person and a change in attitude to the world.

The research results have direct access to the practice of agribusiness. The agroindustrial complex must take on the strategy of creating and managing the information environment.

\section{References}

1. S. Ingebrigtsen, Ove Jakobsen, Ecological Economics 84, 84-90 (2012)

2. R. Gifford, Journal of Environmental Psychology 29, 387-389 (2009)

3. D. Uzzell, N. Räthzel, Journal of Environmental Psychology 29, 340-350 (2009)

4. J.C. Price, Z. Leviston, Journal of Rural Studies 34, 65-78 (2014)

5. G. Fastellini, C. Schillaci, Agricultural Internet of Things and Decision Support for Precision Smart Farmings (2020)

6. L. Prasad Pant, H. Hambly Odame, Journal of Rural Studies 54, 435-450 (2017)

7. S. Ingebrigtsen, O. Jakobsen, Ecological Economics 68, 2777-2784 (2009)

8. G. Winkel, S. Saegert, G.W. Evans, Journal of Environmental Psychology 29, 318-328 (2009)

9. T.B. Long, V. Blok, I. Coninx, Journal of Cleaner Production 112, 9-21 (2016)

10. S.L Nimmagadda, A. Samson, N. Mani, T. Reiners, Procedia Computer Science 159, 1198-1207 (2019)

11. D. D'Amato, N. Droste, K. J. Winkler, A. Toppinen, Journal of Cleaner Production 2301, 460-476 (2019)

12. X. Yin, H. Wang, P. Yin, H. Zhum, Physica A: Statistical Mechanics and its Applications 53215 (2019)

13. L. Klerkx, E. Jakku, P. Labarthe, NJAS - Wageningen Journal of Life Sciences 90-91 (2019)

14. O. Goncharova, Humanitarian and natural science factors for solving environmental problems and sustainable development 1, 55-56 (2011)

15. S. Nedbaeva, Psychological practices of Russian education: technologies for the formation of an environmental personality (2013)

16. S. Nedbaeva, D. Nedbaev, Proceedings of International Conference, 187-191 (2013)

17. J. Dzyaloshinsky, M. Dzyaloshinskaya, Russian Media: how the image of the enemy is created, 262-275 (2019) 